\title{
CRETACEOUS INSECTS FROM LABRADOR 3. A NEW GENUS AND SPECIES OF TERMITE. (ISOPTERA: HODOTERMITIDAE) ${ }^{1}$
}

\author{
By Alfred E. Emerson
}

Department of Zoology, The University of Chicago, and Department of Entomology, American Museum of Natural History.

\section{INTRODUCTION}

The origin and dispersal of numerous higher taxa of termites by mid-Cretaceous times have been postulated from present geographical distributions and the existence of fairly advanced types in early to middle Tertiary deposits (Emerson, 1955, MSS). With the exception of a few extinct genera, the Oligocene termite fauna of Baltic amber includes several genera that are characteristic of present warm temperate climates of Europe and Asia. A recently discovered tropical termite fauna in Mexican amber of Oligocene-Miocene age is generically closely similar to the living fauna of the same region (Emerson, MSS). Heretofore, the earliest known fossil termites were found in Eocene deposits of North America, Australia, and Europe. The few specimens of Eocene age belong to the Mastotermitidae (Emerson, 1965) and Kalotermitidae (Emerson, MSS), but early Oligocene fossils from several deposits including Baltic amber belong to the Hodotermitidae, Mastotermitidae, Kalotermitidae, and Rhinotermitidae. The author and others have considered the fauna of Baltic amber to be of upper Eocene age (Emerson, 1955), but the general concensus now places this fauna in the lower Oligocene. The lack of the most advanced Termitidae from early Tertiary strata is probably due to the general scarcity or absence of this family in temperate climates in the northern hemisphere, and it is predicted that abundant fossils from tropical regions will prove the existence of numerous advanced genera of Termitidae in Cretaceous times. Indeed the tropical fauna of Mexican amber on the Oligocene-Miocene border proves the presence of living genera of various families that include the Termitidae at that time (Emerson, MSS).

The discovery of a fossil termite wing from late Early Cretaceous or early Late Cretaceous (Cenomanian) associated with a warm temperate flora in Labrador is a considerable extension of accurately determined specimens of the order Isoptera backward in geological

\footnotetext{
${ }^{1}$ This investigation was supported by the National Science Foundation (Grant No. G-25146).
} 
time. Earlier reports of fossil termites in Paleozoic deposits are all incorrect because of the erroneous assignment of specimens of other orders to the Isoptera. However, the author is of the opinion, admittedly speculative, that the Isoptera may have originated in early Mesozoic or even late Paleozoic times.

The single forewing here described is without doubt a termite. Only the Isoptera have a humeral suture at the base of the wing that enables the wings to be easily shed at the end of the colonizing flight. The deciduous wings are associated with the strictly social life of these insects, and this Cretaceous fossil is the earliest known social insect, inasmuch as the Labrador horizon is of an earlier age than the recently described fossil ants from Cretaceous amber of New Jersey.

Although the order may be determined accurately, a single forewing, although remarkably complete and well preserved, makes the assignment to other higher taxa somewhat more precarious. In the first place, the variation in the wing venation of species and genera of termites, particularly primitive termites, is great compared to the relative invariability characteristic of many other orders of insects. Wing venation alone cannot be used as confidently for taxonomic and phylogenetic interpretation of termites as it may be for other orders. Slight differences of wing venation, particularly of fossils, have often been interpreted as indications of species or generic differences that are obviously false when the variability of comparable living species is investigated. In the second place, fossils are always fragmentary and show a paucity of characters as compared to abundant series of all castes commonly collected from the living fauna.

In spite of the lack of other characters of the head, thorax, and abdomen, the author feels justified in assigning this forewing to the family Hodotermitidae, the subfamily Cretatermitinae, new subfamily, the genus Cretatermes, new genus, and the species $C$. carpenteri, new species. These taxa and their phylogenetic relationships must be considered as tentative working hypotheses until more abundant and extensive material is available for study and comparison.

\section{Family Hodotermitidae Desneux}

The present status of the Hodotermitidae is discussed by Emerson (in press). The distribution of fossil and living genera is interpreted by Emerson (1955, pp. 473, 482, 484, 490, 492, 498, 499, 502, 506, 507, 509, 516, 5I 7 ).

The author has little doubt that Cretatermes carpenteri agrees with the wing venation of the Hodotermitidae. The wide area occupied 
by the radial sector (Rs) in the outer fourth of the forewing with the innermost branch joined to the inner margin near the wing tip (figs. I, 2) is found only in some of the subfamilies of the Hodotermitidae. The relatively short cubitus $(\mathrm{Cu})$ and the reticulations in the wing membrane between the veins are also in conformity with some subfamilies of the Hodotermitidae.

These combined characters of the forewing eliminate all other known families of termites. It should also be pointed out that this wing venation is associated with characteristic dentition of the imago mandibles, the lack of ocelli, more than two articles in the cerci, together with numerous other characters in more completely preserved fossils and living species of the Hodotermitidae. It is postulated (Emerson, in press) that an unknown ancestral group possessed the ocelli of the Mastotermitidae, Rhinotermitidae, and Termitidae, the dentition of the imago mandible close to that of Archotermopsis and the cockroaches, and a still more ancestral group probably possessed the anal lobe of the hind wing of the Mastotermitidae. Without preserved characters of the head, pronotum, legs, and abdomen of Cretatermes carpenteri, all that can be said at present is that this species most probably belongs to the Hodotermitidae. It is anticipated that this taxonomic assignment will be verified with the discovery of more specimens from the same deposit or of related species from other localities and strata.

\section{Subfamily Cretatermitinae, new subfamily}

In the early stages of this investigation, the author was loath to erect a new monotypic subfamily on the basis of a single fossil forewing, and he still has misgivings. However, he thinks that the tentative assignment to the new subfamily Cretatermitinae is the best nomenclatural and bibliographic symbol to handle the comparative data available. No other known subfamily of the Hodotermitidae has the combination of diagnostic characters illustrated in figs. ', 2, and 3. These include: (I) the evenly curved humeral suture; (2) the greater length of the wing from the inner end of the humeral suture than from the costal end of the humeral suture; (3) the small size of the forewing; (4) the relatively wide wing in proportion to its length; (5) the gradual increase in the width of the area occupied by the radial sector (Rs) from the base to the apical fourth of the wing; (6) the branching of the media (M) in the basal fourth of the wing; (7) the position of the media (M) about half way between the radial sector (Rs) and the cubitus $(\mathrm{Cu})$; and (8) the short cubitus $(\mathrm{Cu})$ not reaching beyond the basal half of 
the inner margin of the wing. Some of these characters are shared with some genera of other subfamilies, but the combination does not fit any presently known subfamily of the Hodotermitidae.

The Termopsinae (Emerson, I933, figs. I3, 30, 40) has a proportionately narrower area occupied by $R s$ in the outer portion of the wing; the length of the wing is considerably larger in all known species; the length of the forewing from the costal end of the humeral suture is about the same as or is shorter than the length of the forewing from the inner end of the humeral suture; Rs is roughly parallel to the costal margin; $\mathrm{M}$ is closer to $\mathrm{Cu}$ than to $\mathrm{Rs}$ in the middle of the wing; and the reticulations enclose smaller and more numerous spaces of the wing membrane.

The Hodotermitinae (Emerson, in press) has well defined inferior branches of Rs reaching the inner margin of the wing behind the tip; the humeral suture of the forewing is somewhat sinuate; the length of the forewing from the costal end of the humeral suture is about equal to the length from the inner end of the humeral suture. The characteristic inferior branches of Rs and the width of the area occupied by Rs and its branches in the outer portion of the wing allow rather easy identification of this subfamily from the forewings alone. It should be pointed out that there is only a little difference in the angles of the branches of Rs in designating a branch as inferior or superior, and in some individual cases the distinction is somewhat arbitrary. From an evolutionary point of view, the transition from superior to inferior branches would seem to be only a slight step, and some other subfamilies such as the Termopsinae, Porotermitinae, and Stolotermitinae have individuals that may have one or more inferior branches of Rs.

The subfamily Porotermitinae with a single genus including three species distributed in temperate areas of southern Australia, South Africa, and Chili, has a fairly straight humeral suture of the forewing with a short curve near the costal end; all known species of Porotermes are much larger than Cretatermes; the wing is proportionately longer compared to its width in most species of Porotermes except $P$. adamsoni in which the proportions are similar to those in Cretatermes; Rs is closely parallel to the costal margin throughout the length of the wing; the superior branches of Rs are thick and strong and are not secondarily branched as in the Cretatermitinae; the main stem of Rs is as strong as the superior branches, but from o-3 inferior branches are as weak as $M$ and reach the inner border of the wing below the tip; $\mathrm{M}$ is about half way between $\mathrm{Rs}$ and $\mathrm{Cu}$ in the 
middle of the wing or may be closer to $\mathrm{Cu}$ than to $\mathrm{Rs}$; and $\mathrm{Cu}$ has from 5-I2 primary branches, the longest extending from about half to four-fifths the length of the wing from the base. The reticulations of the wing membrane do not differ diagnostically from Cretatermitinae, and the inner margin of the wing of the Porotermitinae is longer than the costal margin from the suture in both subfamilies.

Sc, $R_{1}, R_{2}, R_{3}$, or $R_{2+3}$ vary in the Porotermitinae and may not be diagnostically different from this obscure region of the forewing in the single fossil specimen of Cretatermitinae. In the Porotermitinae there may be as few as two branches of the radius emerging from the suture, or there may be a full complement of $S c, R_{1}, R_{2}, R_{3}$, and $R s$ at the suture, thus illustrating the extreme variability of these veins in some species and genera of primitive termites.

In an occasional rather exceptional wing, $M$ may have branches that invade the normal position of Rs, and in such cases the superior branches of $M$ may be as strong as those of Rs and may also reach the costal margin of the outer portion of the forewing. Again, this illustrates the great variability of the venation of these primitive termites and the difficulty of making definitive comparisons. In spite of this degree of variation, however, the general pattern is sufficiently correlated with other characters to indicate valid taxa from the species to the family.

The Stolotermitinae is a subfamily based upon a single genus with six described species, one from temperate South Africa, one from New Zealand, one from Tasmania, one from temperate southeastern Australia, and two (possibly only one) from tropical eastern Australia.

The dentition of the mandibles of Stolotermes is of a very primitive type with strictly homologous teeth to those of cockroaches (Ahmad, 1950), and is only slightly advanced in a few particulars from that of Archotermopsis (Termopsinae) and Ulmeriella (Hodotermitinae). The reticulations of the forewing are not diagnostically different from Cretatermes; the humeral suture of the forewing is fairly straight or convexly curved in contrast to the concave curve of the humeral suture of Cretatermes (fig. 3); the humeral suture slants backward at a sharp angle from the costal to the inner margin; the veins from $\mathrm{Rs}$ to $\mathrm{Cu}$ are bent or curved down toward the inner border near the suture (Hill, I942, fig. I); the costal margin of the forewing is much shorter than the inner margin from the humeral suture to the tip; the shape of the wing may be similar to that of Cretatermes or a little longer compared to width; the linear length 
of the forewing is longer in all species of Stolotermes except $S$. africanus Emerson in which it may be slightly shorter than in Cretatermes carpenteri; $\mathrm{Sc}$ is short; $\mathrm{R}_{1}$ is present and is occasionally branched; $R_{2}$ and $R_{3}$ are absent; $R s$ is gradually wider in the area occupied from the humeral suture to the outer portion of the wing, but is not so proportionately wide as in Cretatermes (figs. I, 2); the superior branches of Rs are closer to each other with less width between them than in Cretatermes; Rs may have from o-2 weaker inferior branches reaching the inner margin near the tip; $M$ is long, not quite reaching the tip of the wing but with the lower branches reaching the inner margin about $1 / 3-3 / 5$ the length of the inner margin from the suture; the first branch of $M$ may be close to the suture as in Cretatermes; $M$ is usually weaker than Rs and is usually closer to $\mathrm{Cu}$ than to $\mathrm{Rs} ; \mathrm{Cu}$ is usually short with 3-7 branches close together, the longest branch reaching the inner margin from I 6 to nearly $\mathrm{I} / 2$ the length of the wing (differs among species). The arolium is absent in the Stolotermitinae, Porotermitinae, and some Hodotermitinae and is present in the Termopsinae and some Hodotermitinae.

The major distinctions between the forewings of Stolotermes and Cretatermes are the shape and position of the humeral suture and the width of the area occupied by Rs and its superior branches about 3/4 the length of the wing from the base.

It is the opinion of the author that the forewing of Cretatermes is closer in more characters to the forewing of various species of Stolotermes than to other subfamilies, and resembles Porotermes next most closely. However, the resemblances and differences of a single forewing are insufficient to warrant any firm conclusion concerning the phylogenetic relationship between the Cretatermitinae and either the Stolotermitinae or the Porotermitinae other than to state that Cretatermes is advanced in its small size, the shape and position of the humeral suture, and in the relatively large spaces between the reticular thickenings of the wing membrane.

\section{PHYLOGENETIC RELATIONS BETWEEN THE SUBFAMILIES OF THE HODOTERMITIDAE}

There would seem to be little doubt that the more primitive genera (Termopsis, Archotermopsis) of the Termopsinae are the most primitive members of the Hodotermitidae, and in several particulars are the most primitive known termites (Emerson, 1933).

Recently (Emerson, in press) a redescription of the fossil genus Ulmeriella of the Hodotermitinae indicates that it is related to but 
is slightly more advanced than Archotermopsis. The various characters of Ulmeriella seem to be derived directly from primitive Termopsinae.

The Stolotermitinae has a very primitive left mandible of the imago (Ahmad, I950; Emerson, 1942, I947), but is derivative in numerous other characters, particularly in the sharply slanting humeral suture of the forewing. L. R. Cleveland discovered that Stolotermes is the only genus of termites that shares a genus of woodingesting intestinal flagellates with the wood-feeding cockroach, Cryptocercus (see Emerson, I961, for a discussion of the evolutionary implications of this discovery). The Stolotermitinae could have branched off from primitive Termopsinae or possibly from primitive Hodotermitinae, but could not have the Porotermitinae in its ancestry as that subfamily is now conceived, primarily because the Porotermitinae has a much reduced second marginal tooth of the left mandible. The Porotermitinae could not be derived from the Stolotermitinae because of the advanced type of humeral suture in the latter subfamily, but it could have branched off from the less primitive Termopsinae or possibly from the Hodotermitinae although only before the specialized harvester behavior had evolved.

Because of the less advanced type of humeral suture, the forewing of the Cretatermitinae could not have arisen from the Stolotermitinae which it resembles in some characters. The wing of the Cretatermitinae might be related remotely to the Porotermitinae, but the data are insufficient to enable us clearly to separate homologous from analogous characters, and parallel reduction from homologous reduction. With more characters of the species available, it may be possible to find consistent patterns of phylogenetic importance, but at present it is necessary to state that several alternative hypotheses of phylogenetic derivation could account for the meager facts. The small size of Cretatermes is reasonably certain to be derivative, but the small size of Stolotermes africanus could have arisen independently, each from more primitive groups of larger size.

With our present information, the Hodotermitidae consist of fossil and living relicts that are spotty and often discontinuous in their distribution. The Porotermitinae and Stolotermitinae, neither represented by known fossils, are found only in the southern hemisphere, and the genera are probably Mesozoic in origin and dispersal because of their existence on different continental masses long isolated from one another. The living and fossil Termopsinae are all found in the north warm temperate zones with a gradation from the most 


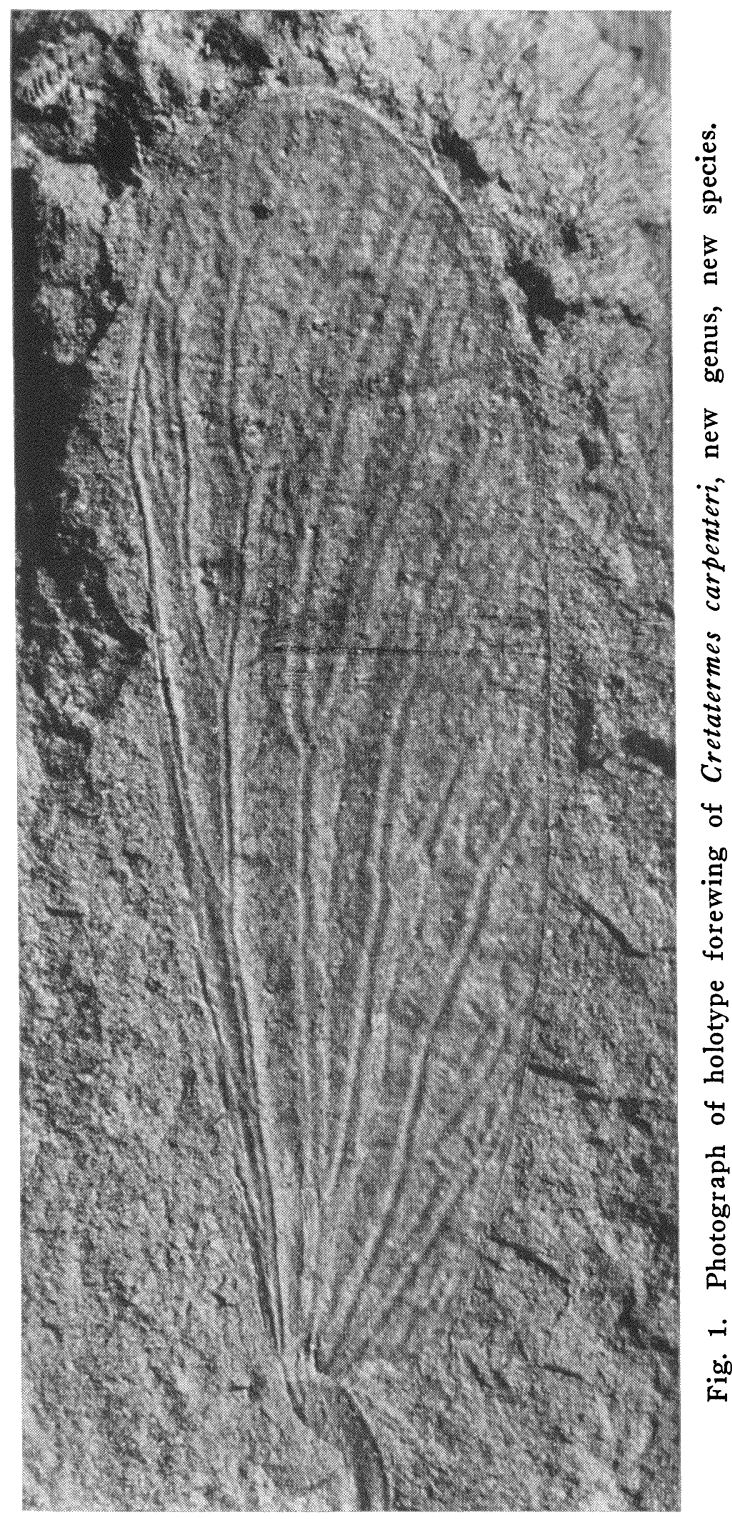


primitive in Eurasia and the derivative genera in Tertiary and present North America. The only known fossil of the subfamily Hodotermitinae is Ulmeriella (Emerson, in press) found in Tertiary temperate deposits of Europe, Asia, and North America, while the living genera (3) of the Hodotermitinae are the desert and steppe harvester termites of temperate and tropical Africa and Asia. These distributions in time and space would seem to indicate a very ancient origin with considerable extinction of intergrades between the relict types of fossils and present survivors (Emerson, 1955, in press).

Cretatermes now provides direct evidence of the existence of a fairly advanced subfamily of the otherwise primitive family of Hodotermitidae in mid-Cretaceous times, and indicates that the origin of this family of termites and the order Isoptera is much earlier than the Labrador deposits. The author suggests that the origin of the Hodotermitidae may be Triassic and that the origin of the Isoptera may be late Paleozoic.

\section{Genus Cretatermes, new genus}

TYPE SPECIES: Cretatermes carpenteri, new species.

With only a single forewing representing a monotypic subfamily, and with no data on the variation within the species or the common characteristics of several species within the genus, the description of the genus and the subfamily coincides for the present.

From the knowledge of species and generic differences in the other subfamilies of Hodotermitidae, however, it is possible to indicate the characters that might be considered of subfamily rank and those that might be considered of generic rank.

The forewings of various genera of Termopsinae show differences in the shape of the humeral suture (Emerson, I933) with very few differences in the wing venation beyond the suture.

Generic characters of the Hodotermitinae are found in the mandibles and the tibial spines, while the wings show little distinction.

The subfamilies of Porotermitinae and Stolotermitinae, each known from a single genus, show little variation of the humeral suture within each genus, and also show numerous generic characters of the wing venation. Smaller degrees of difference in the wing venation indicate species distinctions.

The species within the genera can often be distinguished by the shape of the wing, the relation of length to breadth, small differences in the shape of the humeral suture, and the mean sizes of male and female forewings and other structures. On occasion, specific variation in wing venation can be detected, although many wings must 


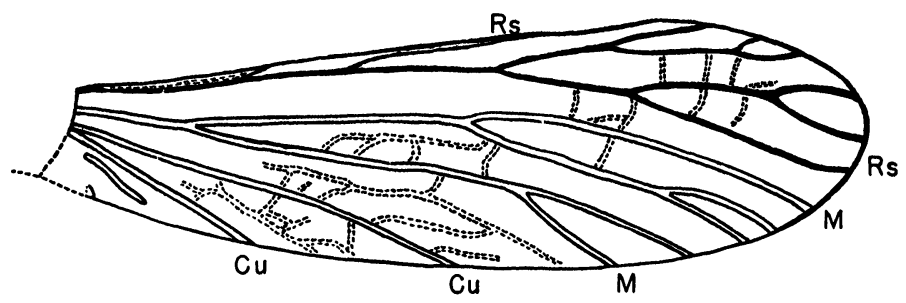

Fig. 2. Drawing of visible veins and reticulations of holotype forewing of Cretatermes carpenteri, new genus, new species. $\mathrm{Rs}=$ radial sector. $\mathrm{M}=$ media. $\mathrm{Cu}=$ Cubitus.

be examined because of the large degree of variation between individuals and even between the right and left wing of the same individual. For adequate species distinction, a set of head, thoracal, and abdominal characters that are correlated with the wing venation should be described, but unfortunately this is not yet possible for Cretatermes carpenteri. The following description, therefore, contains characters of various systematic categories from individual variation to subfamily distinctions, and we must await the discovery of more material and a more thorough study of variation at various related taxonomic levels before we can make taxonomic distinctions and find common qualities of each taxon. This does not mean that the author agrees with those who would eliminate the concepts of species and higher taxonomic categories. On the contrary, he finds the taxa with their shared homologous characters have distinctions that rest upon a wealth of demonstrated biological principles resulting from investigations in a variety of disciplines. Taxonomic and phylogenetic order can be discovered from abundant material subjected to a variety of observational and experimental techniques together with comparative cross-disciplinary studies (Emerson, I96I, in print, MSS).

\section{Gretatermes carpenteri, new species}

RIGHT FOREWING: General shape as in figs. I, 2. The costal margin of the basal Io/1 3 of the wing is slightly convex; tip of wing rounded and about half way between the costal and inner margins; inner margin evenly convex, more curved than the costal margin.

Numerous thickenings or reticulations (archidictyon) of the wing membrane occur between the branches of Rs, between Rs and M, between $\mathrm{M}$ and $\mathrm{Cu}$, and between the branches of both $\mathrm{M}$ and $\mathrm{Cu}$. The enclosed spaces within the reticulum are large compared to those of the Termopsinae and Hodotermitinae. 
Scale broken and the shape is not preserved. The costal margin that often shows important taxonomic distinction is broken off. Some veins seem to cross the humeral suture from the scale to the wing beyond the suture, but some strongly marked structures do not seem to fit the anatomy of the forewing scale and may be other structures separate from the wing that impinge upon it in the preserved scale, or else are marks in the rock.

Humeral suture (fig. 3) seems to be reasonably well preserved. It is evenly curved and slants backward toward its junction with the inner margin. The inner portion of the suture is not as clear as the costal end, but the extension of the clear edges of the suture and the inner margin seem to indicate the true shape and position of the inner portion of the suture. The suture is not angulate in the region of Rs. The inner margin of the wing is somewhat concave where it joins the suture.

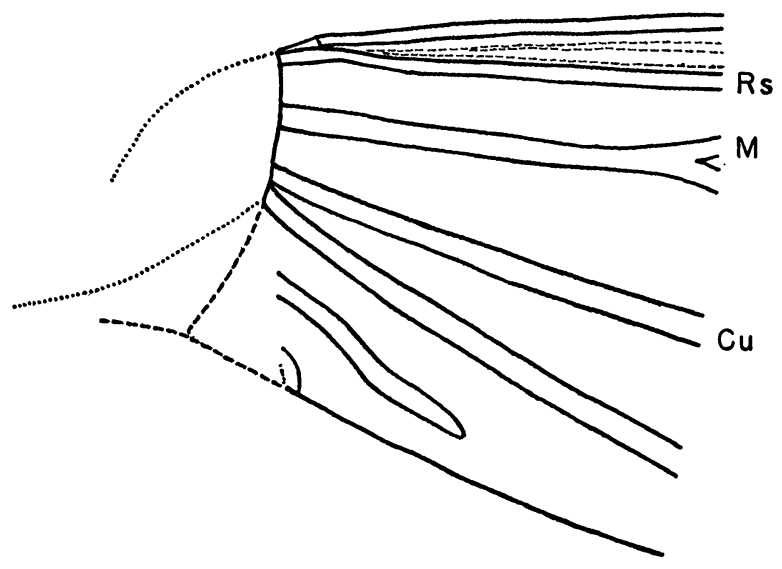

Fig. 3. Drawing of base of holotype forewing of Cretatermes carpenteri, new genus, new species, showing visible veins emerging from the humeral suture.

The veins that emerge from the suture at the costal margin (fig. 3) are somewhat obscure and the wing in this region is either broken or folded. Sc is not clearly visible although it is probably present in well preserved wings. What seems to be the costal margin at the suture may possibly be $R_{1}$ with the actual costal margin either broken or folded under. There are indications of veins between the costal edge and Rs, and it is possible that $R_{1}$ and $R_{2+3}$ are present. These 
veins vary considerably in some genera of Hodotermitidae. A vein joins the costal margin about $1.22 \mathrm{~mm}$. from the suture but it is not clear whether this is the first superior branch of Rs or the end of one of the other branches of the radius. Clear superior branches of Rs occur about $2.63 \mathrm{~mm}$., $3.88 \mathrm{~mm}$., and $5.08 \mathrm{~mm}$. from the suture, and secondary and tertiary branches occur in the apical fourth of the wing. The main stem of Rs ends well below the tip of the wing. In summary, seven and possibly eight branches of Rs reach the costal margin and tip of the wing. The width of the radial sector (Rs) and its branches in the outer fourth of the wing (figs. I, 2) and the gradual divergence of the main stem of the radial sector from the costal margin are interpreted as generic and subfamily characters. The branches of Rs are more defined and are narrower than those of $\mathrm{M}$ and $\mathrm{Cu}$. $\mathrm{M}$ branches into an upper and lower branch about I.OI $\mathrm{mm}$. from the suture, somewhat closer to the suture than in most termites, but the taxonomic significance cannot be interpreted without many more specimens. Five branches of $M$ reach the lower margin in the apical half of the wing, but this character is almost surely variable within the species. The general position of $\mathrm{M}$ about half way between $\mathrm{Rs}$ and $\mathrm{Cu}$ is probably of generic importance and might even be of species importance. $\mathrm{Cu}$ is comparatively short, its longest branch ending close to the middle of the inner margin. The length of $\mathrm{Cu}$ is probably of species or generic importance. $\mathrm{Cu}$ and $\mathrm{M}$ emerge from the suture in a fan-like spread of veins, in this particular strikingly different from the sharply curved veins of Stolotermes.

MEASUREMENTS OF THE FOREWING OF

CRETATERMES CARPENTERI, NEW SPECIES

Length of suture from costal to inner margin about $0.72 \mathrm{~mm}$.

Length of wing from costal end of suture

$7.23 \mathrm{~mm}$.

Length of wing from inner end of suture

$7.42 \mathrm{~mm}$.

Width of wing

$2.23 \mathrm{~mm}$.

Widest width of radial sector

$0.93 \mathrm{~mm}$.

Width between Rs and $M$ near middle of wing

Width between upper and lower branches of $M$ in

$0.39 \mathrm{~mm}$. middle of wing

Widest width between $\mathrm{M}$ and $\mathrm{Cu}$ about $\mathrm{I} / 3$ length of wing from suture

$0.37 \mathrm{~mm}$.

$0.44 \mathrm{~mm}$.

SPECIMEN: Holotype, right forewing and counterpart impressions, of Cenomanian age, at the border between Lower and Upper Cretaceous, in a bed of hard ferruginous argillite associated with 
rubble ores at the Redmond No. I deposit near Schefferville (latitude $54^{\circ} 5 \mathrm{O}^{\prime} \mathrm{N}$., longitude $67^{\circ} \mathrm{OO}^{\prime} \mathrm{W}$.) in the Knob Lake district, Labrador; collected by Professor Erling Dorf. The holotype is No. 87270, Invertebrate Paleontology collections, Princeton University. From associated fossil plants, Dorf ( 1959) suggests that the climate at the time of preservation was warm temperate.

\section{ACKNOWLEDGEMENTS}

The author is indebted to Frank M. Carpenter of the Biological Laboratories, Harvard University, for making the specimen available to me and for his numerous critical comments through many years on various aspects of insect paleontology. The author also wishes to thank his wife, Eleanor Fish Emerson, for her valued assistance in the preparation and editing of the manuscript.

\section{SUMMARY}

The earliest known specimen of a termite (Isoptera), that is also the earliest known fossil of a strictly social insect, is described and figured from a forewing from mid-Cretaceous deposits near Schefferville, Labrador. The forewing is classified as Cretatermes carpenteri, new genus, new species, and included in the subfamily Cretatermitinae, new subfamily of the family Hodotermitidae. Systematic and phylogenetic interpretations and comparisons are included.

\section{BIBLIOGRAPHY}

AHMAD, M.

1950. The phylogeny of termite genera based on imago-worker mandiDORF, ERLING bles. Bull. Amer. Mus. Nat. Hist., 95 : 37-86.

1959. Cretaceous flora from beds associated with iron-ore deposits in the Labrador trough. Program of Meetings, Geol. Soc. Amer., 1959: 33A.

EMERSON, A. E.

1933. A revision of the genera of fossil and recent Termopsinae (Isoptera). Univ. California Publ. Ent., 6: 165-196.

1942. The relations of a relict South African termite (Isoptera, Hodotermitidae, Stolotermes). Amer. Mus. Novitates, 1187: 1-12.

1947. The imago of Stolotermes africanus Emerson. Jour. Ent. Soc. So. Africa, 9: 127-129.

1955. Geographical origins and dispersions of termite genera. Fieldiana: Zool., 37: 465-521.

1961. Vestigial characters of termites and processes of regressive evolution. Evolution, 15: 115-131. 
1965. A review of the Mastotermitidae (Isoptera), including a new fossil genus from Brazil. Amer. Mus. Novitates, 2236: 1-46.

(In press) A revision of the fossil genus Ulmeriella (Isoptera; Hodotermitidae; Hodotermitinae). Amer. Mus. Novitates.

(In preparation) MSS on fossil Kalotermitidae, Rhinotermitidae, and Termitidae.

HiLl, G. F.

1942. Termites (Isoptera) from the Australian region. Melbourne, Australia, Council for Scientific and Industrial Research, pp. 1479. 

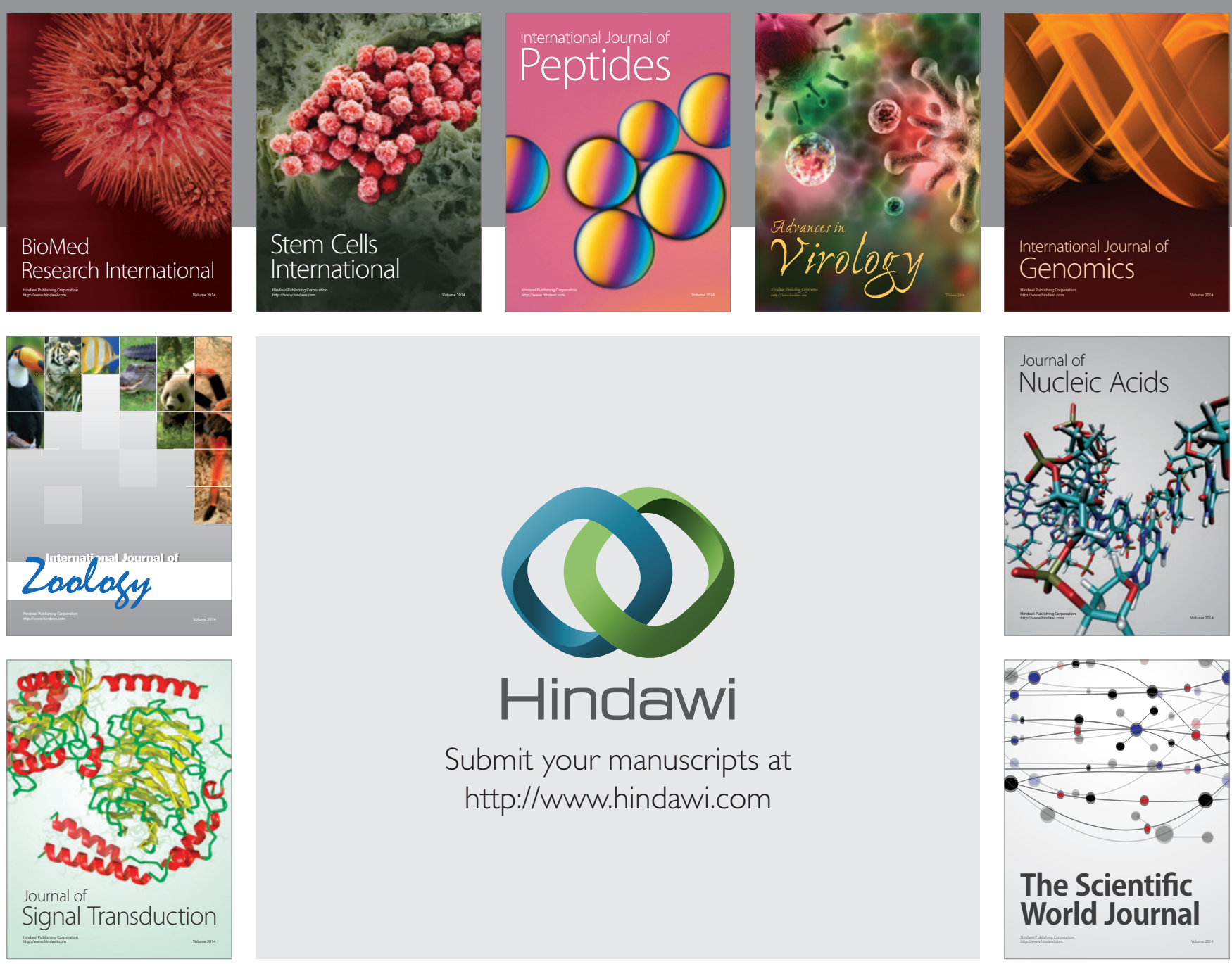

Submit your manuscripts at

http://www.hindawi.com
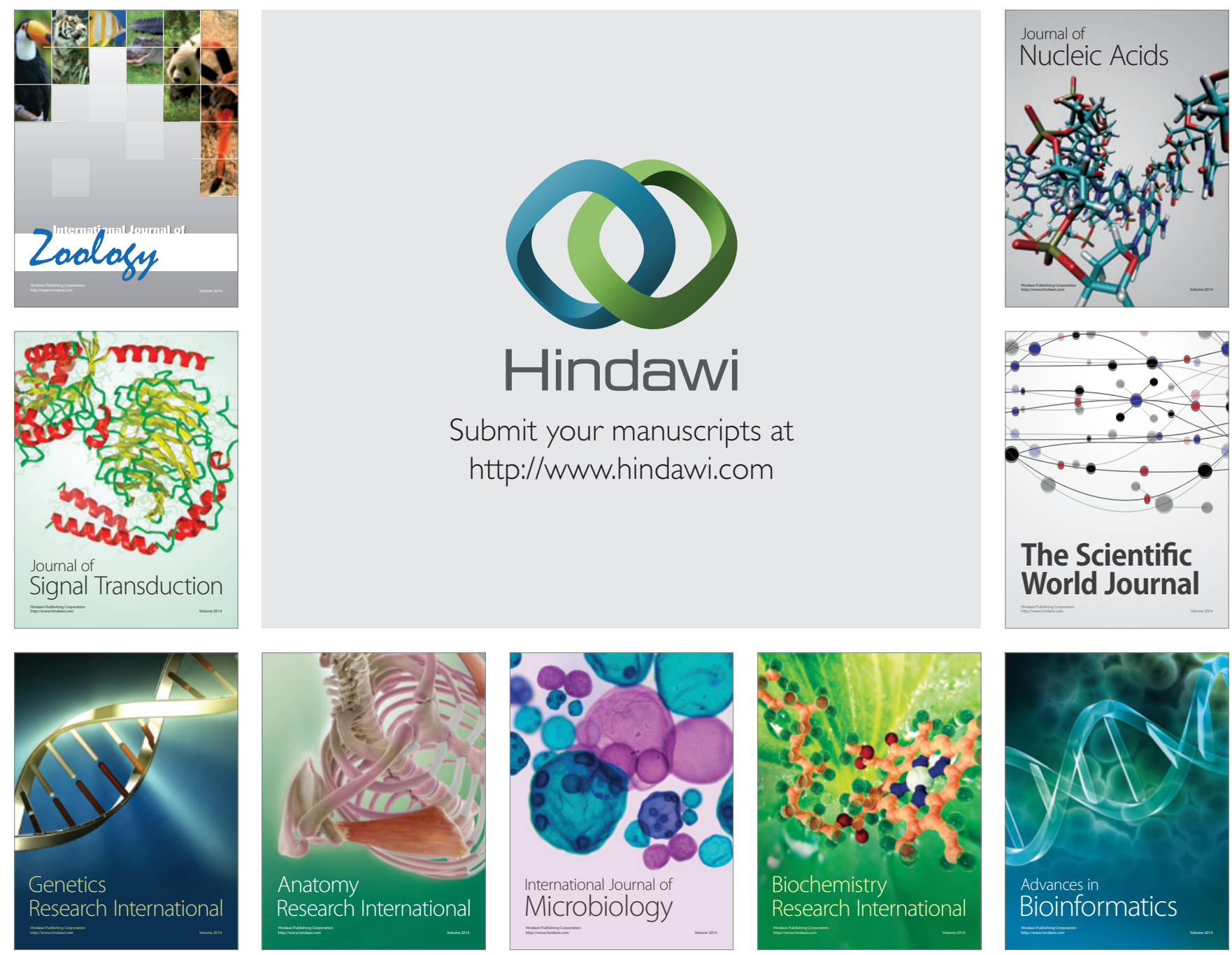

The Scientific World Journal
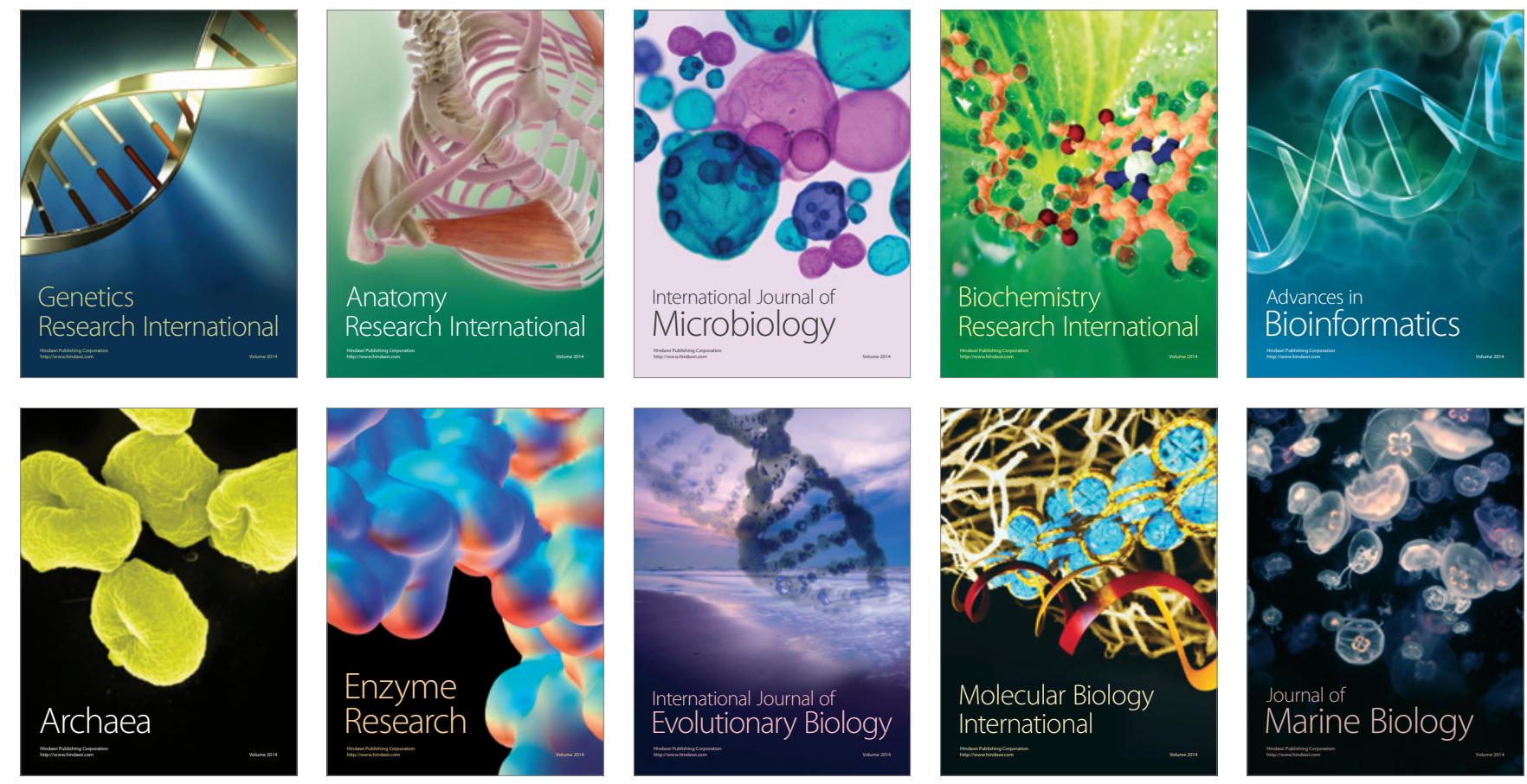